Ambiente \& Água - An Interdisciplinary Journal of Applied Science
ISSN 1980-993X - doi:10.4136/1980-993X
www.ambi-agua.net
E-mail: ambi-agua@agro.unitau.br

\title{
Diagnóstico físico-ambiental como subsídio a identificação de áreas vulneráveis à erosão na bacia hidrográfica do Ribeirão do Espírito Santo, Juiz de Fora (MG), Brasil
}

\author{
doi: 10.4136/ambi-agua.1416
}

Received: 05 Jun. 2014; Accepted: 26 Aug. 2014

\author{
Vívian Gemiliano Pinto ${ }^{1 *}$; Ricardo Neves de Souza Lima ${ }^{2}$; \\ Celso Bandeira de Melo Ribeiro ${ }^{3}$; Pedro José de Oliveira Machado ${ }^{3}$ \\ ${ }^{\mathbf{1}}$ Instituto Federal de Educação Ciência e Tecnologia do Sudeste de Minas Gerais, Juiz de Fora, MG, Brasil \\ ${ }^{2}$ Instituto Brasileiro de Geografia e Estatística (IBGE), Rio de Janeiro, RJ, Brasil \\ ${ }^{3}$ Universidade Federal de Juiz de Fora (UFJF), Juiz de Fora, MG, Brasil \\ *Autor correspondente: e-mail: viviangemiliano@gmail.com, \\ riksou@yahoo.com.br, celso.bandeira@ufjf.edu.br, \\ pjomachado@gmail.com
}

\section{RESUMO}

Um diagnóstico físico-ambiental pode auxiliar no entendimento dos mecanismos que atuam nas áreas naturais e antropizadas, permitindo orientar as atividades a serem desenvolvidas, de maneira a subsidiar ações preservacionistas e conservacionistas, evitandose intervenções irreversíveis e conservando os recursos naturais da região. Neste contexto, o objetivo deste trabalho foi estudar a Bacia Hidrográfica do Ribeirão do Espírito Santo (BHRES), em Juiz de Fora, Minas Gerais, Brasil, através de um diagnóstico físico ambiental para identificação da vulnerabilidade à erosão superficial, utilizando como ferramentas parâmetros morfométricos, declividade do terreno, uso/cobertura do solo e tipo de solo na região. Apesar de a BHRES ser eminentemente rural, suas características morfométricas, declividade, uso/cobertura e tipo de solo indicam alta vulnerabilidade à erosão superficial, demandando que se adotem ações mitigadoras para preservação das áreas de regeneração da vegetação arbórea, bem como planejamento do manejo de plantações florestais e pastagens, de forma a conservar os corpos hídricos, controlar o crescimento da silvicultura na região, minimizar áreas de solo exposto e gerenciar o crescimento urbano e industrial, uma vez que esta bacia abriga um dos mais importantes mananciais de abastecimento de Juiz de Fora.

Palavras-chave: cobertura do solo, morfometria, zoneamento ambiental.

\section{Physical and environmental diagnosis as a subsidy identifying vulnerable areas to erosion in the Ribeirão do Espírito Santo watershed in Juiz de Fora (MG), Brazil}

\section{ABSTRACT}

A physical environmental diagnosis may help understand the mechanisms that operate in natural and disturbed areas, allowing guidance of the activities to be developed in order to subsidize preservationist and conservationist actions. Thereby, avoiding irreversible interventions and conserving the region's natural resources. In this context, the aim of this 
work is to study the Espírito Santo River Watershed (ESRW), in Juiz de Fora, Minas Gerais, Brazil, by doing a physical environmental assessment to identify vulnerability to surface erosion. In order to achieve that, morphometric parameters, terrain slope, use/land cover and soil type in the region were used. Although ESRW is predominantly rural, its morphometric characteristics, slope, use/cover and soil type indicate high vulnerability to surface erosion. Our findings show a demand by the adoption of mitigation measures for the preservation of regenerating wooded areas, as well as planning the management of forest plantations and pastures. Hence conserving water bodies, controlling the growth of forestry in the region, minimizing areas of exposed soil and managing urban and industrial growth, since this basin is home to one of the most important sources of supply to Juiz de Fora.

Keywords: environmental zoning, land cover, morphometry.

\section{INTRODUÇÃO}

A esculturação do modelo terrestre é fortemente influenciada pelas bacias hidrográficas e suas redes de drenagem, uma vez que as direções preferenciais dos fluxos superficiais definem os mecanismos erosivo-deposicionais preponderantes e são resultados da interação do uso e ocupação do solo, clima, aspectos geológicos, tipo de solo, relevo e cobertura vegetal (Bueno et al., 2010; Veríssimo et al., 1996).

A erosão é um problema ambiental crítico para os ecossistemas terrestres em todo o mundo (Pimentel, 2006). A vegetação mantém uma relação com o processo de erosão natural, atenuando a ação das chuvas no solo. Porém, quando esta vegetação é removida pode se instalar um processo erosivo, que é considerado acelerado quando ocorre de forma mais rápida do que os processos de formação do solo, não permitindo que esse se regenere (Abdon, 2004; Thomaz e Antoneli, 2008). A erosão tem como principais consequências o assoreamento de cursos d'água, degradação do solo, maior frequência e intensidade de enchentes e alterações ecológicas que afetam fauna e flora.

Inúmeros parâmetros podem subsidiar um estudo de vulnerabilidade ambiental. Beltrame (1994) utiliza vegetação, clima, características geológicas, pedológicas e relevo. Ross (1994) considera a declividade, tipos de solos, clima, dissecação do relevo e a proteção dos solos dada pela cobertura vegetal. Crepani et al. (2001), Nascimento e Dominguez (2009) e Melo e Santos (2010) promovem o cruzamento entre geologia, morfometria, formas de relevo, declividade, tipos de solos, vegetação e clima.

Neste contexto, o objetivo deste trabalho foi estudar a Bacia Hidrográfica do Ribeirão do Espírito Santo (BHRES), em Juiz de Fora, Minas Gerais, Brasil, através de um diagnóstico físico-ambiental para identificação da vulnerabilidade à erosão superficial, utilizando como ferramentas parâmetros morfométricos, declividade do terreno, uso/cobertura do solo e tipo de solo na região.

\section{MATERIAL E MÉTODOS}

\section{1. Área de estudo}

A área de estudo compreende a BHRES localizada na região noroeste do município de Juiz de Fora, Minas Gerais, Brasil, compreendida na área delimitada pelas coordenadas

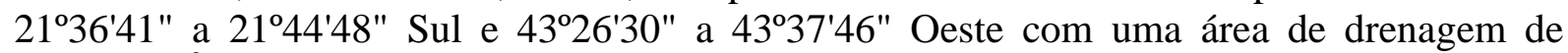
$151,49 \mathrm{~km}^{2}$ (Figura 1).

O Ribeirão Espírito Santo, afluente da margem direita do Rio Paraibuna, que por sua vez é afluente da margem esquerda do Rio Paraíba do Sul, é um importante manancial da cidade de Juiz de Fora, responsável pelo abastecimento de água de cerca de $40 \%$ da população, 
produzindo 620 litros de água tratada por segundo, conforme indicado pela Companhia de Saneamento Municipal (Juiz de Fora, 2010).

No século XIX, a BHRES era ocupada por lavouras de café, o que fez com que boa parte da cobertura vegetal arbórea fosse retirada. Com o abandono das plantações, em virtude dos baixos preços e da intensa industrialização pela qual a cidade passou, essas áreas foram ocupadas por pastagens, em sua maioria, e por áreas de regeneração da vegetação arbórea. Atualmente identificam-se outros sinais das atividades antrópicas, como abertura de estradas, granjeamentos, silvicultura e expansão do distrito industrial da cidade (Faria et al., 2003).

\subsection{Individualização das bacias de drenagem}

O Modelo Digital de Elevação (MDE) da BHRES foi gerado em ambiente SIG (Sistema de Informação Geográfica), utilizando o software ArcGIS Desktop, versão 10.1 (ESRI, 2013). As informações topográficas para a geração do MDE foram provenientes de levantamento por LIDAR (Light Detection and Ranging) e restituição aerofotogramétrica realizados pela Prefeitura de Juiz de Fora. Em razão da escala de estudo e para melhor desempenho computacional, a resolução espacial do MDE foi degradada de $1 \mathrm{~m}$ para $5 \mathrm{~m}$.

O Modelo Digital de Elevação Hidrologicamente Consistente (MDEHC) foi gerado a partir do MDE, utilizando ferramentas de geoprocessamento disponíveis no pacote Hydrology, no módulo Spatial Analyst do SIG ArcGIS, versão 10.1 (ESRI, 2013). Foi aplicado inicialmente a função Fill para preenchimento das depressões espúrias no MDE, ou seja, nivelamento de áreas para permitir a determinação do sentido do escoamento superficial de modo coerente. Em seguida, foi utilizada a função Flow Direction para determinar em cada pixel a direção do escoamento superficial conforme o método desenvolvido por (Jenson e Domingue, 1988).

Como alguns autores (Crepani et al., 2001; Oliveira et al., 2009) sugerem a divisão da área a ser estudada para identificação de áreas vulneráveis, na sequência foi aplicada a função Watershed, para definir em um modelo raster, as áreas de drenagem de interesse. Nesse caso foram utilizados como parâmetros de entrada o raster da direção do escoamento (Flow Direction) e pontos para representar os exutórios de cada sub-bacia. Considerou-se como exutório as confluências dos córregos Taquaras, Gouveia e Penido com o Ribeirão do Espírito Santo, como mostra a Figura 1, enquanto que para a Área de Drenagem de Jusante da Margem Esquerda (ADJME) e Área de Drenagem de Jusante da Margem Direita (ADJMD) foi considerada a foz do Ribeirão Espírito Santo no Rio Paraibuna. Por fim as áreas de drenagem geradas em SIG no formato raster foram convertidas para o formato vetorial.

O MDEHC foi validado segundo o Padrão de Exatidão Cartográfica Altimétrica (PEC) estabelecido pelo Decreto ${ }^{\circ}$. 89.817 de 20 de Junho de 1984 (Brasil, 1984). Para a validação foram levantados 31 pontos na BHRES, utilizando-se GPS, e a altitude desses pontos foram comparadas às altitudes determinadas pelo MDEHC, seguindo metodologia descrita por Poleto et al. (2008). O MDEHC se enquadrou no padrão de exatidão cartográfica classe A, mostrando-se consistente e apresentando precisões compatíveis para a realização de análises hidrológicas apesar de apresentar tendências e erros sistemáticos na imagem referente à altitude.

Para a identificação dos corpos d'água foram utilizados dados vetoriais digitais referentes à hidrografia das cartas topográficas do Instituto Brasileiro de Geografia e Estatística (IBGE), folhas Ewbank da Câmara (SF-23-X-C-VI-2) e Juiz de Fora (SF-23-X-D-IV-1), ambas na escala de 1:50.000.

A BHRES foi dividida em três sub-bacias (Figura 1): sub-bacia do Córrego Taquaras (SBCT), que contém a nascente do Ribeirão Espírito Santo, contudo foi utilizada a nomenclatura do Córrego Taquaras, uma vez que este é o maior curso em extensão da sub-bacia e para distingui-la da BHRES propriamente dita; sub-bacia do Córrego Gouveia 
(SBCG); sub-bacia do Córrego Penido (SBCP); e duas áreas de drenagem, ADJME e ADJMD, mais próximas ao exutório.

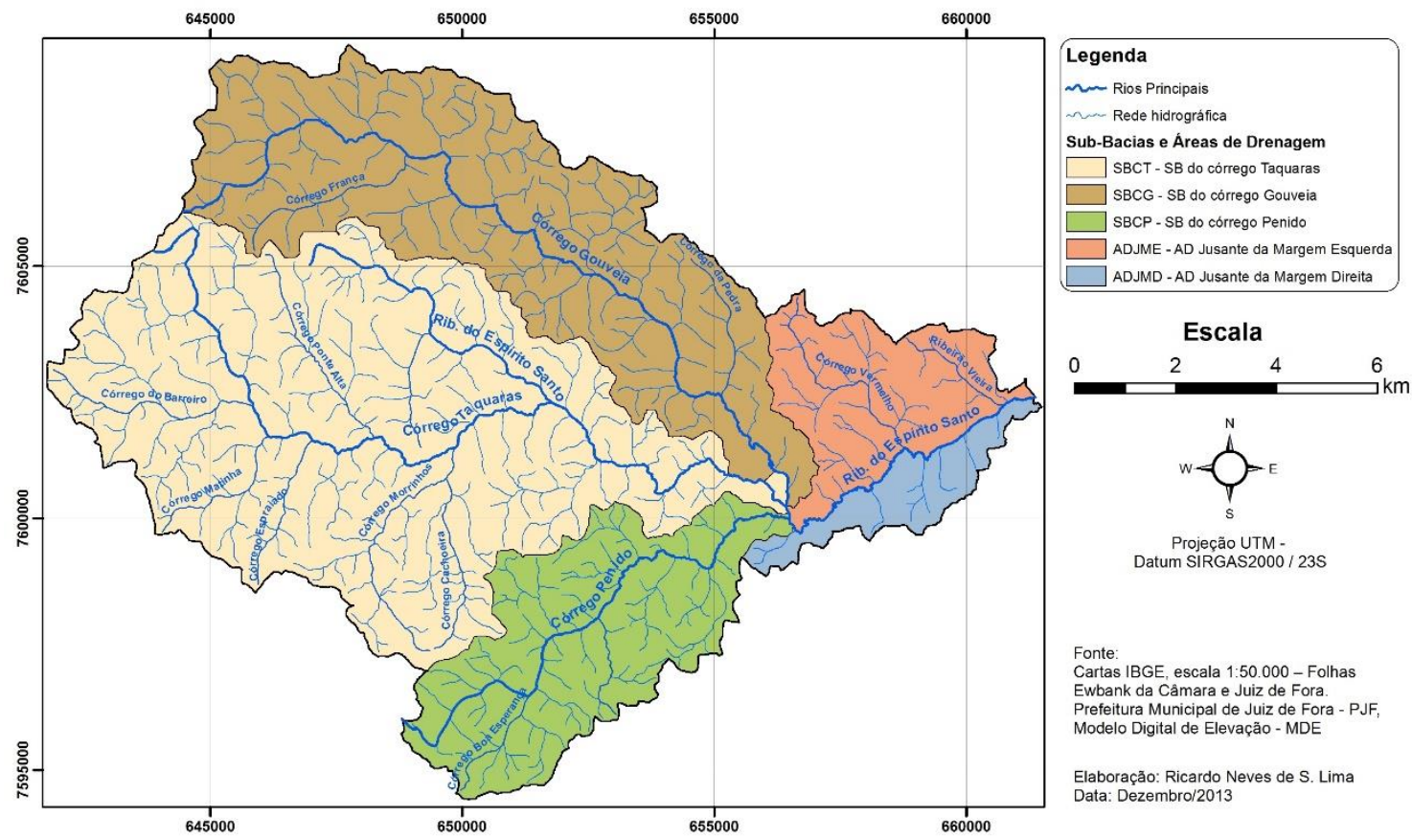

Figura 1. Distribuição espacial das três sub-bacias e das duas áreas de drenagem na Bacia Hidrográfica do Ribeirão do Espírito Santo.

Fonte: (Lima, 2013).

A maior sub-bacia da BHRES é a SBCT, com área de drenagem de $68,7 \mathrm{~km}^{2}$, correspondendo a 45,35\% da área da bacia; seguida da SBCG, com área de $42,73 \mathrm{~km}^{2}(28,2 \%$ da BHRES); SBCP, com área de 22,71 km² (14,99\% da BHRES); ADJME com 12,37 km² ( $8,17 \%$ da BHRES); e ADJMD com 4,98 $\mathrm{km}^{2}$ (3,29\% da BHRES).

Para o diagnóstico físico-ambiental da BHRES, sub-bacias e áreas de drenagem foram considerados os parâmetros de morfometria, declividade, uso e cobertura do solo e classificação dos solos. Esses parâmetros foram escolhidos por serem fundamentais ao estudo da erosão superficial, e consequentemente, ao processo de assoreamento (Machado, 2012).

A vulnerabilidade de cada sub-bacia e área de drenagem foi calculada em função de cada um dos parâmetros considerados no estudo, estabelecendo-se uma escala de vulnerabilidade: variável de um (muito baixa) a cinco (muito alta), segundo os diferentes intervalos, conforme o parâmetro analisado. Os valores da escala de vulnerabilidade funcionaram como "pesos", a serem atribuídos às diferentes áreas de cada sub-bacia ou área de drenagem.

\subsection{Morfometria}

A caracterização morfométrica de bacias hidrográficas é uma ferramenta importante para subsidiar o planejamento territorial visando a preservação ambiental e a manutenção da produção de água em quantidade e qualidade (Nardini et al., 2013). A combinação de dados morfométricos auxiliam na diferenciação de áreas homogêneas, revelando indicadores físicos específicos de forma a qualificarem as alterações ambientais.

Neste estudo, os parâmetros morfométricos utilizados foram: Densidade de Drenagem, Comprimento de Rampa Médio do Escoamento Superficial e Índice de Rugosidade, descritos na Tabela 1. 
Tabela 1. Descrição dos parâmetros morfométricos utilizados na área de estudo, fórmulas e seu significado.

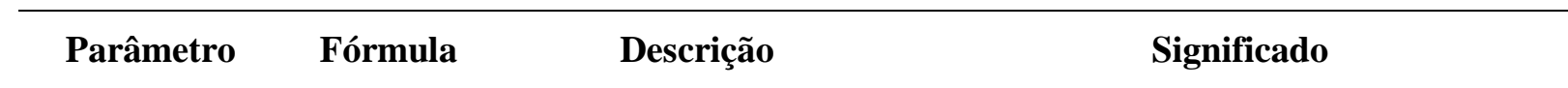

$\begin{array}{ll}\text { Densidade de } & \mathrm{Dd}=\frac{\mathrm{L}_{\mathrm{t}}}{\mathrm{A}}\end{array} \quad \begin{aligned} & \text { Lt é comprimento total de } \\ & \text { todos os canais }(\mathrm{km}) ; \\ & \text { Arenagem (Dd) a área de drenagem } \\ & \text { total }\left(\mathrm{km}^{2}\right) .\end{aligned}$

Comprimento de Rampa Médio do Escoamento Superficial (Cr)

$$
\mathrm{Cr}=\frac{1}{4 \mathrm{Dd}} \quad \begin{aligned}
& \text { Dd é a densidade de } \\
& \text { drenagem }\left(\mathrm{km} \mathrm{km}^{-2}\right) .
\end{aligned}
$$

H é a amplitude Índice de $\quad \mathrm{Ir}=\mathrm{H} * \mathrm{Dd} \quad$ altimétrica da bacia $(\mathrm{km})$; Rugosidade (Ir) Ir $=\mathrm{H} * \mathrm{Dd} \quad$ Dd é a densidade de drenagem $\left(\mathrm{km} \mathrm{km}^{-2}\right)$.
Está relacionada com declividade do relevo, cobertura vegetal, resistência e permeabilidade do solo (Rocha e Kurtz, 2001).

É definido como sendo a distância média em que a água da chuva teria que escoar sobre o terreno de uma bacia, caso o escoamento se desse em linha reta desde onde a chuva cai até o ponto mais próximo do leito de um curso d’água da bacia (Villela e Mattos, 1975).

Em uma mesma região, Ir elevado implica em maior potencial de erosão por processos hídricos (Rocha e Kurtz, 2001).

Para cada parâmetro morfométrico calculado, para cada sub-bacia ou área de drenagem, atribuiu-se peso 5 ao maior valor, uma vez que representava a condição mais favorável à erosão; e peso 1 para o menor, condição menos favorável à erosão. Dividindo-se o intervalo entre os valores extremos em cinco classes, obteve-se uma escala de vulnerabilidade, que recebeu pesos variando de 1 a 5 , correspondendo, respectivamente, à: muito baixa, baixa, média, alta e muito alta vulnerabilidade.

Após a determinação do peso para cada um dos parâmetros mofométricos (Densidade de Drenagem, Comprimento de Rampa Médio do Escoamento Superficial e Índice de Rugosidade), estes foram somados para cada sub-bacia ou área de drenagem, cujo somatório poderia variar de 3 a 15, uma vez que foram utilizados três parâmetros cujos pesos variavam de 1 a 5. Dividindo-se o intervalo gerado pelo somatório dos pesos relativos aos parâmetros morfométricos em cinco classes obteve-se o intervalo de domínio das classes de vulnerabilidade para morfometria, apresentada na coluna um da Tabela 2.

Tabela 2. Intervalos de domínio das classes de vulnerabilidade para morfometria, declividade, tipo de solo e determinação da vulnerabilidade ambiental da área de estudo.

\begin{tabular}{ccccc}
\hline Morfometria & $\begin{array}{c}\text { Declividade, } \\
\text { Uso e cobertura do } \\
\text { solo e Tipo de solo }\end{array}$ & $\begin{array}{c}\text { Diagnóstico Físico- } \\
\text { ambiental }\end{array}$ & $\begin{array}{c}\text { Vulnerabilidade à } \\
\text { erosão superficial }\end{array}$ & $\begin{array}{c}\text { Escala de } \\
\text { vulnerabilidade }\end{array}$ \\
\hline De 3 até 5,4 & Entre 1 e 1,8 & Entre 4 e 7,2 & Muito baixa & 1 \\
$>5,4$ até 7,8 & $>1,8$ até 2,6 & $>7,2$ até 10,4 & Baixa & 2 \\
$>7,8$ até 10,2 & $>2,6$ até 3,4 & $>10,4$ até 13,6 & Média & 3 \\
$>10,2$ até 12,6 & $>3,4$ até 4,2 & $>13,6$ até 16,8 & Alta & 4 \\
$>12,6$ até 15 & $>4,2$ até 5 & $>16,8$ até 20 & Muito Alta & 5 \\
\hline
\end{tabular}




\subsection{Declividade}

A declividade é uma característica topográfica diretamente relacionada à erosão superficial, pois tem influência na infiltração das águas das chuvas e na velocidade de escoamento superficial (Valladares et al., 2012). A influência desse parâmetro pode ser hierarquizada, como o fizeram diversos pesquisadores (Beltrame, 1994; Crepani et al., 2001; Klais et al., 2012; Ross, 1994). No presente trabalho adotou-se, para as classes de relevo preconizadas pela EMBRAPA (2006), a escala de vulnerabilidade utilizada por Machado (2012), dada as semelhanças entre as áreas de estudo (primeira, quarta e quinta colunas da Tabela 3).

Tabela 3. Escala de vulnerabilidade para os parâmetros declividade, uso e cobertura do solo e tipos de solos.

\begin{tabular}{cllcl}
\hline $\begin{array}{c}\text { Intervalos de } \\
\text { declividade }\end{array}$ & $\begin{array}{c}\text { Uso e Cobertura } \\
\text { do solo }\end{array}$ & Tipos de solos & $\begin{array}{c}\text { Vulnerabilidade } \\
\text { à erosão } \\
\text { superficial }\end{array}$ & $\begin{array}{c}\text { Escala de } \\
\text { vulnerabilidade }\end{array}$ \\
\hline 0 a $3 \%$ & Floresta & - & 1 & Muito baixa \\
$>3$ a $8 \%$ & Agrossilvicultura & $\begin{array}{l}\text { Latossolos Vermelhos e } \\
\text { Vermelhos-amarelos }\end{array}$ & 2 & Baixa \\
$>8$ a $20 \%$ & Silvicultura & Latossolos Amarelos & 3 & Média \\
$>20$ a $45 \%$ & Pastagem & Cambissolos & 4 & Alta \\
$>45 \%$ & $\begin{array}{l}\text { Área construída } \\
\text { Solo exposto }\end{array}$ & - & 5 & Muito Alta \\
\hline
\end{tabular}

Para obter-se a vulnerabilidade à erosão superficial relativa à declividade, multiplicou-se os pesos das respectivas classes de declividade indicados na Tabela 3 pelas áreas correspondentes, somou-se as áreas ponderadas de cada unidade de estudo e dividiu-se pela área real de cada uma delas. Os quocientes gerados para cada sub-bacia e áreas de drenagem variaram de 1 a 5 , cujo intervalo foi dividido em 5 classes apresentadas na Tabela 2 (segunda, quarta e quinta colunas), para identificação da vulnerabilidade à erosão superficial devido à declividade, associada à sua respectiva escala de vulnerabilidade.

\subsection{Uso e cobertura do solo}

Para o mapeamento dos principais tipos de uso e cobertura do solo na BHRES foi realizada a classificação de imagens do satélite RapidEye, com resolução espacial de $5 \mathrm{~m}$ e data de passagem de 27/04/2010. O mapeamento das classes de uso/cobertura do solo foi executado por intermédio de uma classificação automática supervisionada utilizando o método de máxima verossimilhança Gaussiana (Maxver), disponível no software ENVI ${ }^{\circledR}$ versão 4.8 .

Faria e Fernandes Filho (2013), Oliveira et al. (2013) e Souza et al. (2011) destacaram o bom desempenho do método Maxver em imagens do RapidEye quando o processo de seleção das amostras de treinamento representam a diversidade espectral da classe a ser mapeada. No caso específico deste trabalho este treinamento foi realizado com as classes corpos d'água, pastagem, floresta, solo exposto e área construída.

Contudo, para distinguir superfícies com características espectrais similares, como áreas de regeneração da vegetação arbórea e silvicultura, que inicialmente haviam sido classificadas como floresta, utilizaram-se imagens de alta resolução do aplicativo Google Earth, versão gratuita, e procedeu-se identificação manual de áreas cobertas por plantios de eucalipto e 
áreas de agrossilvicultura, eucalipto e pasto, as quais foram posteriormente vetorizadas e incluídas no mapa final de uso e cobertura do solo.

A hierarquização do tipo de uso do solo e/ou cobertura vegetal associada à erosão superficial é bastante diversa, conforme as características específicas do local de estudo (Crepani et al., 2001; Ribeiro e Campos, 2007). A densidade de cobertura vegetal do terreno é um fator de proteção contra os processos morfogenéticos que se traduzem na forma de erosão. Dessa forma para altas densidades de cobertura, os valores atribuídos na escala de vulnerabilidade se aproximam da estabilidade (Crepani et al., 2001). Na tentativa de ponderar a densidade de cobertura vegetal associada à vulnerabilidade à erosão, adotou-se uma escala de vulnerabilidade (segunda, quarta e quinta colunas da Tabela 3), idêntica àquela adotada por Machado (2012).

Para o cálculo da vulnerabilidade à erosão superficial relativa ao uso/cobertura do solo, multiplicaram-se os pesos dos respectivos uso/cobertura do solo indicados na Tabela 3 pelas áreas correspondentes, somou-se as áreas ponderadas de cada unidade de estudo e dividiu-se pela área real de cada uma delas. Em seguida, utilizando-se metodologia análoga àquela adotada para declividade, associou-se a vulnerabilidade à erosão superficial gerada pelo uso e cobertura do solo à sua respectiva escala de vulnerabilidade (segunda, quarta e quinta colunas da Tabela 2).

\subsection{Classificação de solos}

A classificação de solos na BHRES foi realizada a partir da vetorização, em SIG, das Unidades de Mapeamento apresentadas no Mapa de Solos do Estado de Minas Gerais, Folha 4, na escala 1:650.000 (FEAM, 2010).

Tomando-se por base os trabalhos de Crepani et al. (2001), Machado (2012) e Ross (1994), estabeleceu-se a escala de vulnerabilidade para os solos da BHRES, segundo sua erodibilidade, com valores de 1 a 5, como apresentados na Tabela 3 (terceira, quarta e quinta colunas).

Para se determinar a vulnerabilidade à erosão superficial relacionada às classes de solo, multiplicou-se os pesos dos respectivos tipos de solo, indicados na Tabela 3, pelas áreas correspondentes. Somaram-se as áreas ponderadas de cada unidade de estudo e dividiu-se pela área real de cada uma delas. Em seguida, utilizando-se metodologia idêntica àquelas adotadas para declividade e uso e cobertura do solo associou-se a vulnerabilidade à erosão superficial gerada pela classificação dos solos à sua respectiva escala de vulnerabilidade (segunda, quarta e quinta colunas da Tabela 2).

\subsection{Diagnóstico de vulnerabilidade físico-ambiental}

Para a determinação da vulnerabilidade físico-ambiental à erosão superficial, somaram-se os valores obtidos na escala de vulnerabilidade para os quatro parâmetros analisados: morfometria, declividade, uso/cobertura do solo e classificação do solo em cada sub-bacia e área de drenagem da BHRES. Como o valor obtido para cada uma das unidades de estudo poderia variar de 4 (mínimo) a 20 (máximo), uma vez que foram utilizados quatro parâmetros cujos pesos variavam de 1 a 5, dividindo-se o intervalo gerado pelo somatório dos pesos relativos em cinco classes obteve-se o intervalo de domínio das classes de vulnerabilidade apresentadas na terceira coluna da Tabela 2.

\section{RESULTADOS E DISCUSSÃO}

\subsection{Características morfométricas}

A BHRES possui padrão de drenagem dendrítico, com grande quantidade de afluentes e subafluentes. Villela e Mattos (1975) classificam bacias com valores de densidade de 
drenagem entre 0,5 e $1,5 \mathrm{~km} . \mathrm{km}^{-2}$ como drenagem regular, entre 1,5 e 2,5 km. $\mathrm{km}^{-2}$ como boa drenagem, entre 2,5 e $3,5 \mathrm{~km} \cdot \mathrm{km}^{-2}$ como muito boa e acima de $3,5 \mathrm{~km} . \mathrm{km}^{-2}$ como excepcionalmente bem drenadas. A BHRES e suas sub-bacias são muito bem drenadas com densidades de drenagem variando de 2,67 (SBCG) a 3,08 km. $\mathrm{km}^{-2}$ (SBCP). Também consideradas com alta capacidade de drenagem, de acordo com a classificação proposta por Beltrame (1994).

Estudos em outras bacias da região sudeste do Brasil também identificaram boa densidade de drenagem. Silva e Tonello (2014) identificaram densidade de drenagem de $2,72 \mathrm{~km} \cdot \mathrm{km}^{-2}$ na bacia hidrográfica do Ribeirão dos Pinheirinhos em Brotas, São Paulo; Lima et al. (2011) estimaram em 2,37 km. $\mathrm{km}^{-2}$ na bacia hidrográfica do Rio Preto, Minas Gerais; Santos et al. (2012) identificaram 3,49 e $4,10 \mathrm{~km} \cdot \mathrm{km}^{-2}$, respectivamente, nas sub-bacias hidrográficas de Perdizes e Fojo no município de Campos do Jordão, SP. Em contrapartida, na região nordeste brasileira, Rocha et al. (2014) estudando a sub-bacia do rio Poxim-Açu, Sergipe, encontraram densidade de drenagem de $1,82 \mathrm{~km} \cdot \mathrm{km}^{-2}$, valor mais próximo àqueles encontrados na ADJME $\left(2,32 \mathrm{~km} \cdot \mathrm{km}^{-2}\right)$ e ADJMD $\left(1,43 \mathrm{~km} \cdot \mathrm{km}^{-2}\right)$.

Altas densidades de drenagem podem indicar solos pouco permeáveis (Christofoletti, 1980) ou pequena cobertura vegetal ou relevo acidentado, ou ainda situações concomitantes, que favorecem o escoamento superficial e consequentemente o maior carreamento de partículas do solo (Rocha e Kurtz, 2001).

O Comprimento de Rampa Médio do Escoamento Superficial (Cr) também influi diretamente na perda de solo, uma vez que quanto maior for a sua extensão maior tenderá a ser a velocidade do escoamento superficial (Villela e Mattos, 1975). O Cr não apresenta muita discrepância entre as sub-bacias, variando de 0,0811(SBCP) a 0,0936 (SBCG). Porém, são nas áreas de drenagem que se identificam os maiores valores de $\mathrm{Cr}$, principalmente na ADJMD $(0,1751)$, o que pode influenciar a perda de solo.

O Índice de Rugosidade (Ir) combina a qualidade de declividade e comprimento das vertentes, com a densidade de drenagem (Christofoletti, 1980), seus valores máximo e mínimo indicam, respectivamente, os maiores e menores potenciais de erosão por processos hídricos na BHRES. As três sub-bacias apresentam Ir variando de 0,717 (SBCG) a 0,775 (SBCT) e a ADJMD apresenta o menor Ir $(0,293)$.

Após a atribuição de pesos a cada parâmetro morfométrico, tornou-se possível hierarquizar as áreas de estudo por parâmetro. Somando-se o peso atribuído a cada parâmetro, de cada unidade de estudo e comparando-os com a Tabela 2, identificou-se que as SBCT, SBCP e a BHRES apresentam alta vulnerabilidade à erosão superficial em relação aos parâmetros morfométricos analisados. Enquanto a SBCG apresenta média vulnerabilidade, e a ADJMD e ADJME apresentam baixa vulnerabilidade, devido principalmente a contribuição da Densidade de Drenagem e do Índice de Rugosidade.

\subsection{Declividade}

Todas as unidades de estudo possuem mais de $40 \%$ de sua área com declividade entre 20 e $45 \%$ (Figura $2 \mathrm{a}$ ), e mais de $20 \%$ de área com declividade acima de $45 \%$, exceto a ADJMD que possui $17 \%$ de área com declividade acima de $45 \%$, e quase $13 \%$ de sua área com declividade entre 0 e $3 \%$.

Em terrenos mais íngremes, a água tende a escoar com maior velocidade, dificultando a infiltração e favorecendo o processo erosivo (Valladares et al., 2012). A BHRES e todas as unidades de estudo, isoladamente, apresentaram alta vulnerabilidade à erosão superficial devido à declividade (Tabela 4), inclusive a ADJMD, ou seja, o maior percentual de área com declividade entre 0 e $3 \%$ não foi suficientemente relevante para fazer com que essa apresentasse vulnerabilidade à erosão superficial devido à declividade inferior as demais áreas estudadas. 
Tabela 4. Determinação da vulnerabilidade à erosão superficial devido à declividade.

\begin{tabular}{|c|c|c|c|c|c|c|c|c|c|c|}
\hline \multirow{4}{*}{$\begin{array}{r}\text { Unidade } \\
\text { de estudo }\end{array}$} & \multicolumn{4}{|c|}{ Classes de Declividade - Área $\left(\mathrm{km}^{2}\right)$} & \multirow{3}{*}{$\begin{array}{r}\text { Acima } \\
\text { de } 45 \% \\
\end{array}$} & \multirow{4}{*}{$\begin{array}{c}\text { Área } \\
\text { real } \\
\text { total } \\
\left(\mathbf{k m}^{2}\right)\end{array}$} & \multirow{4}{*}{ 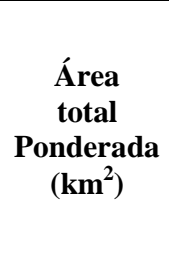 } & \multirow{4}{*}{ 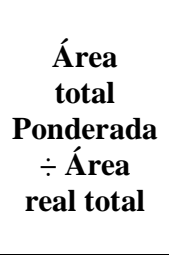 } & \multirow{4}{*}{$\begin{array}{c}\text { Escala de } \\
\text { vulnerabilidade }\end{array}$} & \multirow{4}{*}{$\begin{array}{l}\text { Vulnerabilidade } \\
\text { à erosão } \\
\text { superficial }\end{array}$} \\
\hline & 0 a $3 \%$ & 3 a $8 \%$ & 8 a $20 \%$ & 20 a $45 \%$ & & & & & & \\
\hline & \multicolumn{4}{|c|}{ Peso } & & & & & & \\
\hline & 1 & 2 & 3 & 4 & 5 & & & & & \\
\hline SBCT & 2,50 & 5,84 & 10,82 & 33,46 & 16,09 & 68,70 & 260,90 & 3,80 & 4 & Alta \\
\hline SBCG & 1,49 & 3,54 & 6,39 & 21,01 & 10,30 & 42,73 & 163,26 & 3,82 & 4 & Alta \\
\hline $\mathrm{SBCP}$ & 1,16 & 2,57 & 3,89 & 9,44 & 5,64 & 22,71 & 83,96 & 3,70 & 4 & Alta \\
\hline ADJME & 0,72 & 1,25 & 1,84 & 5,26 & 3,30 & 12,37 & 46,29 & 3,74 & 4 & Alta \\
\hline ADJMD & 0,64 & 0,49 & 0,87 & 2,13 & 0,85 & 4,98 & 17,00 & 3,41 & 4 & Alta \\
\hline BHRES & 6,51 & 13,70 & 23,80 & 71,31 & 36,18 & 151,49 & 571,41 & 3,77 & 4 & Alta \\
\hline
\end{tabular}
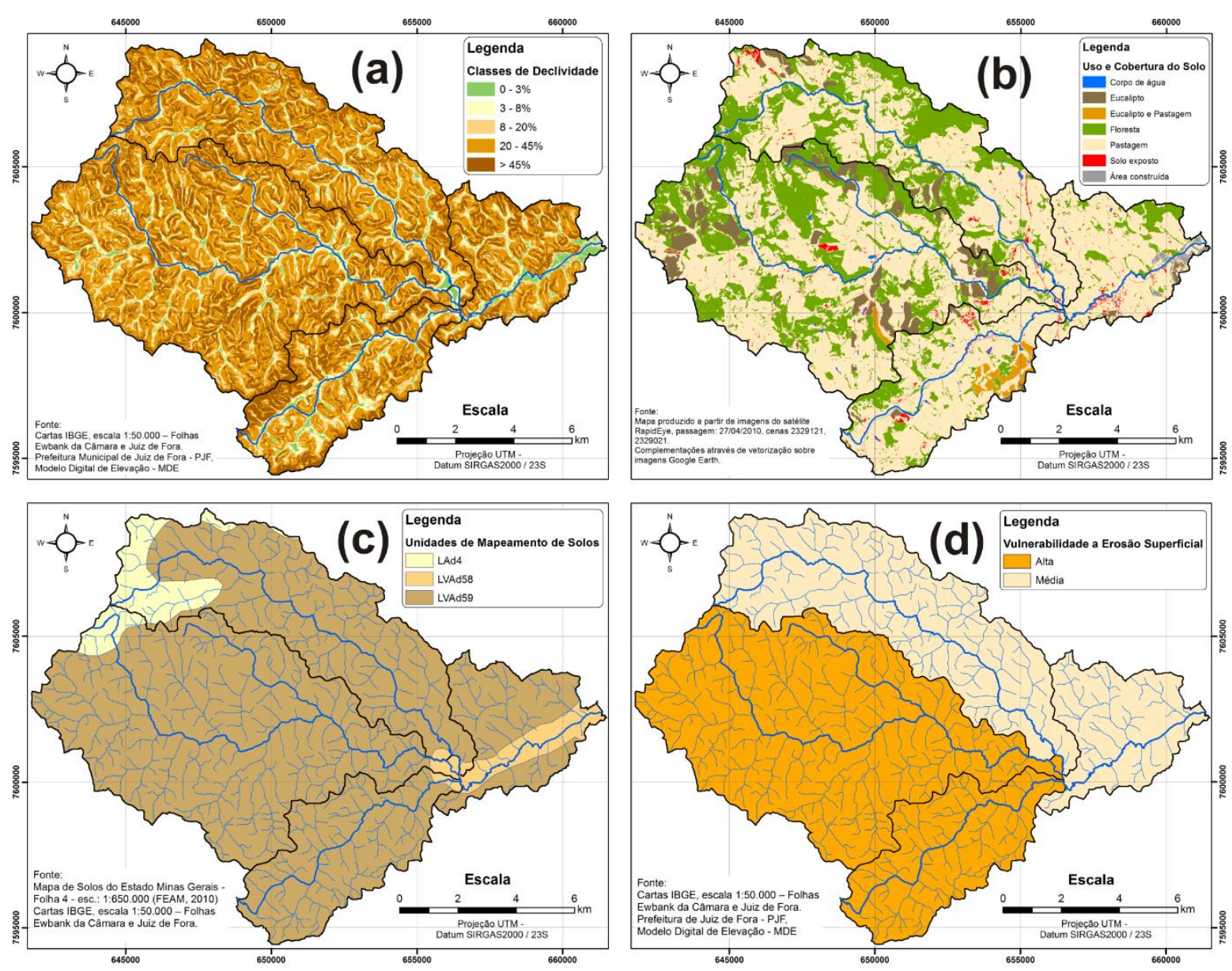

Figura 2. Mapas de declividade, uso e cobertura do solo, classificação do solo e vulnerabilidade à erosão superficial nas sub-bacias e áreas de drenagem da BHRES.

(a) Declividade (b) Uso e cobertura do solo (c) Classificação do solo (d) Vulnerabilidade à erosão superficial.

Fonte: (Lima, 2013). 


\subsection{Uso e cobertura do solo}

A BHRES é caracterizada por predominante ocupação rural (Figura 2b), com 98,24\% da sua área ocupada por pastagens, silvicultura e mata. Sendo que nas SBCT e SBCG não foram identificadas áreas construídas, pois as construções nessas áreas se restringiram a pequenas edificações rurais dificultando seu reconhecimento no nível de resolução utilizado. Nessas duas sub-bacias, apesar do predomínio de pastagens, acima de $60 \%$, identificam-se as maiores áreas de mata da BHRES, porém na SBCT cerca de $10 \%$ da área já é ocupada pela silvicultura, sendo $6,68 \mathrm{~km}^{2}(9,72 \%)$ de plantações de eucalipto e $0,24 \mathrm{~km}^{2}(0,35 \%) \mathrm{de}$ agrossilvicultura (eucalipto e pastagem).

Cabe considerar que plantações florestais de crescimento rápido como o Eucalipto consomem mais água do que a vegetação de menor porte e culturas agrícolas não irrigadas, podendo em algumas situações levar à uma redução significativa do deflúvio na escala de microbacias (Lima, 2010; Poore e Fries, 1985). Neste contexto, Calder (2007) alerta que o percentual de ocupação da área da microbacia pelas plantações florestais é um fator muito importante para a ocorrência ou não de redução de deflúvio, uma vez que alguns trabalhos em microbacias experimentais indicaram alteração no deflúvio em situações em que as plantações florestais ocupavam apenas até $20 \%$ da área da microbacia hidrográfica. Sendo assim, talvez seja o momento para a criação de políticas públicas que: possam controlar o uso e ocupação da BHRES pela silvicultura, de forma a manter a disponibilidade hídrica, uma vez que a bacia contém um dos mais importantes mananciais da cidade de Juiz de Fora; e, de forma simultânea, corrobore para a minimização da erodibilidade do solo por meio da agrossilvicultura, evitando situações de solo exposto, comuns na época do corte do eucalipto.

A BHRES possui $28,95 \%$ de sua área coberta por floresta, ou seja, áreas de regeneração da vegetação arbórea. Com maiores concentrações na SBCG $(34,70 \%)$ e SBCT $(33,85 \%)$, porém na SBCP $(15,12 \%)$, ADJME $(17,54 \%)$ e principalmente ADJMD (3,25\%) estes percentuais caem expressivamente.

Já as áreas de solo exposto correspondem a 1,17\% da BHRES, sendo uma parte delas correspondente às estradas vicinais, sem pavimentação. Contudo, merecem atenção algumas áreas de solo exposto concentradas, uma em área de cabeceira na SBCG, e outra em área central da SBCT (Figura 2b).

A SBCP é a sub-bacia com menor área de solo exposto, porém maior percentual $(1,45 \%)$, o que é justificado pelo avanço do processo de ocupação, principalmente granjeamentos. Além disto, entre as sub-bacias, foi a única onde foi possível mensurar a área construída, $0,09 \mathrm{~km}^{2}(0,39 \%)$. Possui $75,77 \%$ de sua área ocupada por pastagens e apenas $15,12 \%$ de área de regeneração da vegetação arbórea.

Porém, a área mais antropizada da BHRES é a ADJMD, com 0,34 $\mathrm{km}^{2}$ de área construída, seguida pela ADJME, com $0,20 \mathrm{~km}^{2}$. A área construída corresponde a apenas $0,42 \%$ da BHRES, concentrada próxima ao exutório, especialmente em uma área que abrange parte do distrito industrial de Juiz de Fora.

Apesar da predominante cobertura vegetal, a BHRES, SBCT e SBCG apresentaram média vulnerabilidade à erosão superficial (Tabela 5). Entretanto a SBCP, ADJME e ADJMD, todas mais próximas ao exutório, apresentaram alta vulnerabilidade dada as características de ocupação já descritas.

\subsection{Classificação dos solos}

Tomando-se por base o mapeamento de solos do Estado de Minas Gerais (FEAM, 2010), a BHRES é predominantemente composta de latossolo vermelho-amarelo, LVAd59; as cabeceiras dos Córregos Taquaras e Gouveia são compostas por latossolo amarelo, LAd4;e as áreas próximas ao exutório, nas sub-bacias, e regiões marginais ao Ribeirão do Espírito Santo, nas áreas de drenagem, são compostas por latossolo vermelho-amarelo, LVAd58 (Figura 2c). 
Cabe destacar que perfis de solos localizados em áreas muito declivosas tendem a serem menos espessos, pois tal posição favorece a morfogênese, levando estes solos a um constante rejuvenescimento por erosão (Ippoliti et al., 2005).

As sub-bacias e áreas de drenagem da BHRES não se distinguem em relação à vulnerabilidade à erosão superficial devido às classes de solo (Tabela 6), todas apresentando média vulnerabilidade.

Tabela 5. Determinação da vulnerabilidade à erosão superficial devido ao uso/cobertura do solo.

\begin{tabular}{|c|c|c|c|c|c|c|c|c|c|c|c|}
\hline \multirow{4}{*}{$\begin{array}{l}\text { Unidade } \\
\text { de estudo }\end{array}$} & \multicolumn{6}{|c|}{ Uso/cobertura do solo - Área $\left(\mathbf{k m}^{2}\right)$} & \multirow{4}{*}{$\begin{array}{l}\text { Área } \\
\text { real } \\
\text { total } \\
\left(\mathbf{k m}^{2}\right)\end{array}$} & \multirow{4}{*}{$\begin{array}{l}\text { Área } \\
\text { total } \\
\text { ponderada } \\
\left(\mathbf{k m}^{2}\right)\end{array}$} & \multirow{4}{*}{$\begin{array}{l}\text { Área total } \\
\text { ponderada } \\
\div \text { Área } \\
\text { real total }\end{array}$} & \multirow{4}{*}{$\begin{array}{c}\text { Escala de } \\
\text { vulnerabilidade }\end{array}$} & \multirow{4}{*}{$\begin{array}{l}\text { Vulnerabilidade } \\
\text { à erosão } \\
\text { superficial }\end{array}$} \\
\hline & $\mathbf{A}$ & B & $\mathbf{C}$ & D & $\mathbf{E}$ & $\mathbf{F}$ & & & & & \\
\hline & \multicolumn{6}{|c|}{ Peso } & & & & & \\
\hline & 5 & 3 & 2 & 1 & 4 & 5 & & & & & \\
\hline SBCT & 0,00 & 6,68 & 0,24 & 23,26 & 37,83 & 0,59 & 68,59 & 198,03 & 2,89 & 3 & Média \\
\hline SBCG & 0,00 & 1,16 & 0,00 & 14,82 & 26,19 & 0,50 & 42,67 & 125,55 & 2,94 & 3 & Média \\
\hline $\mathrm{SBCP}$ & 0,09 & 0,35 & 1,22 & 3,43 & 17,20 & 0,33 & 22,63 & 77,83 & 3,44 & 4 & Alta \\
\hline ADJME & 0,20 & 0,00 & 0,00 & 2,17 & 9,87 & 0,12 & 12,36 & 43,24 & 3,50 & 4 & Alta \\
\hline ADJMD & 0,34 & 0,24 & 0,00 & 0,16 & 3,98 & 0,24 & 4,97 & 19,73 & 3,97 & 4 & Alta \\
\hline BHRES & 0,63 & 8,43 & 1,46 & 43,85 & 95,08 & 1,77 & 151,22 & 464,38 & 3,07 & 3 & Média \\
\hline
\end{tabular}

A: Área construída; B: Silvicultura; C: Agrossilvicultura; D: Floresta; E; Pastagem; F: Solo exposto.

Tabela 6. Determinação da vulnerabilidade à erosão superficial devido tipo de solo.

\begin{tabular}{|c|c|c|c|c|c|c|c|c|c|c|c|c|c|c|c|}
\hline \multirow{6}{*}{$\begin{array}{l}\text { Unidade } \\
\text { de estudo }\end{array}$} & \multicolumn{10}{|c|}{ Tipos de solo - Área $\left(\mathbf{k m}^{2}\right)$} & \multirow{6}{*}{ 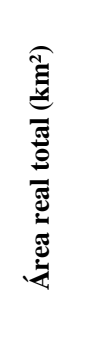 } & \multirow{6}{*}{ 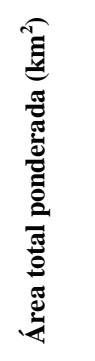 } & \multirow{6}{*}{ 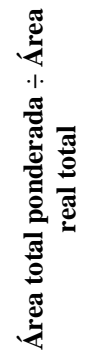 } & \multirow{6}{*}{ 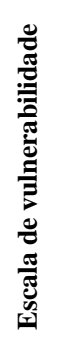 } & \multirow{6}{*}{ 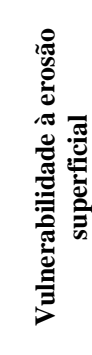 } \\
\hline & \multicolumn{4}{|c|}{ LVAd58 $^{1}$} & \multicolumn{3}{|c|}{ LVAd59 $^{1}$} & \multicolumn{3}{|c|}{ LAd4 $^{1}$} & & & & & \\
\hline & $\mathbf{L V A}^{2}$ & $\mathbf{L A}^{\mathbf{3}}$ & $\mathbf{C}^{5}$ & $\mathbf{L} \mathbf{V}^{4}$ & $\mathbf{L V A}^{2}$ & $\mathbf{L A}^{\mathbf{3}}$ & $\mathrm{C}^{5}$ & $\mathbf{L A}^{\mathbf{3}}$ & $\mathbf{L V A}^{2}$ & $\mathbf{C}^{5}$ & & & & & \\
\hline & $40 \%$ & $30 \%$ & $20 \%$ & $10 \%$ & $60 \%$ & $20 \%$ & $20 \%$ & $40 \%$ & $40 \%$ & $20 \%$ & & & & & \\
\hline & & & & & & eso & & & & & & & & & \\
\hline & 2 & 3 & 4 & 2 & 2 & 3 & 4 & 3 & 2 & 4 & & & & & \\
\hline SBCT & 0,23 & 0,17 & 0,11 & 0,06 & 1,28 & 0,43 & 0,43 & 26,40 & 26,40 & 13,20 & 68,70 & 191,88 & 2,79 & 3 & Média \\
\hline SBCG & 0,16 & 0,12 & 0,08 & 0,04 & 4,10 & 1,37 & 1,37 & 14,20 & 14,20 & 7,10 & 42,73 & 118,22 & 2,77 & 3 & Média \\
\hline SBCP & 0,15 & 0,11 & 0,07 & 0,04 & - & - & - & 8,93 & 8,93 & 4,47 & 22,71 & 63,54 & 2,80 & 3 & Média \\
\hline ADJME & 1,03 & 0,77 & 0,51 & 0,26 & - & - & - & 3,92 & 3,92 & 1,96 & 12,37 & 34,39 & 2,78 & 3 & Média \\
\hline ADJMD & 0,72 & 0,54 & 0,36 & 0,18 & - & - & - & 1,28 & 1,28 & 0,64 & 4,98 & 13,76 & 2,76 & 3 & Média \\
\hline BHRES & 2,29 & 1,71 & 1,14 & 0,57 & 5,38 & 1,79 & 1,79 & 54,72 & 54,72 & 27,36 & 151,49 & 421,80 & 2,78 & 3 & Média \\
\hline
\end{tabular}

${ }^{1}$ Tipos de latossolos que apresentam suas composições discriminadas na tabela; ${ }^{2}$ Latossolo vermelho-amarelo; ${ }^{3}$ latossolo amarelo; ${ }^{4}$ latossolo vermelho; ${ }^{5}$ cambissolo. 


\subsection{Diagnóstico físico-ambiental da BHRES}

De maneira geral a BHRES é altamente vulnerável à erosão superficial, fortemente impactada pela declividade acentuada e grande cobertura de pastagens. O tipo de solo e a declividade do terreno, não auxiliaram na distinção entre as áreas mais e menos favoráveis à erosão, uma vez que toda a bacia indicou média suscetibilidade a erosão devido ao tipo de solo e alta suscetibilidade devido à declividade. Os parâmetros morfometria e uso e cobertura do solo foram os fatores preponderantes.

A SBCP e SBCT possuem as densidades de drenagem e os índices de rugosidade mais favoráveis à erosão superficial. Com relação ao uso e cobertura do solo, a SBCP é a sub-bacia que apresenta maiores sinais da intervenção antrópica, com menor percentual de cobertura florestal e maior percentual de cobertura por pastagens, o que culminou em alta vulnerabilidade à erosão superficial (Figura 2d). Enquanto a SBCT, apesar de um uso/cobertura medianamente vulnerável, dada a morfometria altamente vulnerável, conduziu também ao diagnóstico final de altamente vulnerável.

Contudo, a área mais antropizada da BHRES, a ADJMD que possui o maior percentual de área construída, pastagem, eucalipto e solo exposto, e, consequentemente, o menor percentual de floresta $(3,25 \%)$, foi classificada como de média vulnerabilidade dadas suas características morfométricas, assim como a ADJME (Figura 2d). A SBCG também foi classificada de média vulnerabilidade, uma vez que possui características morfométricas um pouco menos severas que as demais sub-bacias.

\section{CONCLUSÃO}

A metodologia utilizada, com implementação de parâmetros morfométricos, declividade do terreno, uso/cobertura do solo e tipo de solo, em ambiente SIG, mostrou-se adequada para realizar um diagnóstico físico-ambiental visando a identificação da vulnerabilidade à erosão superficial na Bacia Hidrográfica do Ribeirão do Espírito Santo.

Os resultados indicaram alta vulnerabilidade das unidades hidrográficas à erosão nas subbacias do Córrego Taquaras (SBCT) e Sub-Bacia do Córrego Penido (SBCP) e média na SubBacia do Córrego Gouveia (SBCG) e Área de Drenagem de Jusante da Margem Esquerda e Direita (ADJME e ADJMD).

A predominância de alta susceptibilidade à erosão na Bacia Hidrográfica do Ribeirão do Espírito Santo sugere a necessidade de se implementarem medidas mitigadoras direcionadas para a preservação das áreas de regeneração da vegetação arbórea, bem como um plano de manejo de plantações florestais e pastagens, de forma a conservar os corpos hídricos, controlar o crescimento da silvicultura na região, minimizar áreas de solo exposto, principalmente na SBCP e SBCT, que abrigam um manancial estratégico para a cidade de Juiz de Fora - MG.

O estudo realizado indicou a potencialidade à erosão nas bacias, e teve como vantagem a necessidade de utilização de um pequeno número de parâmetros representativos (pedológicos, fisiográficos e de uso do solo), especializados em ambiente SIG. Entretanto, recomenda-se que em estudos futuros, sejam utilizadas metodologias que levem em consideração outros parâmetros relacionados aos processos erosivos do solo, tais como: climáticos (precipitação), manejo do solo e técnicas conservacionistas (edáficas, vegetativas e mecânicas).

\section{AGRADECIMENTOS}

Os autores agradecem à Fundação de Amparo à Pesquisa do Estado de Minas Gerais - FAPEMIG pelo apoio financeiro a execução do projeto (Processo TEC_APQ.02118-12). 


\section{REFERÊNCIAS}

ABDON, M. D. M. Os impactos ambientais no meio físico - erosão e assoreamento na Bacia Hidrográfica do Rio Taquari, MS, em decorrência da pecuária. 2004. 302f. Tese (Doutorado em Engenharia Ambiental) - Universidade de São Paulo, São Carlos, 2004.

BELTRAME, Â. D. V. Diagnóstico do meio físico de bacias hidrográficas: modelo e aplicação. Florianópolis: Ed. da UFSC, 1994. 111p.

BRASIL. Casa Civil. Decreto $n^{\circ}$ 89.817, de 20 de junho de 1984. Estabelece as instruções reguladoras das normas técnicas da cartografia nacional. Diário Oficial da União, Brasília, 1984.

BUENO, C. R. P.; ARRAES, C. L.; PEREIRA, G. T.; CORA, J. E.; CAMPOS, S. Análise multivariada na determinação do risco de erosão em solos sob irrigação. Irriga, Botucatu, v. 15, n. 1, p. 23-35, 2010.

CALDER, I. R. Forests and water-Ensuring forest benefits outweigh water costs. Forest Ecology and Management, v. 251, n. 1-2, p. 110-120, 2007. http://dx.doi.org/10.1016/j.foreco.2007.06.015

CHRISTOFOLETTI, A. A análise de bacias hidrográficas. In: Geomorfologia. São Paulo: Edgard Blücher, 1980. cap. 4, p.102-127.

CREPANI, E.; MEDEIROS, J. S. D.; FILHO, P. H.; FLORENZANO, T. G.; DUARTE, V.; BARBOSA, C. C. F. Sensoriamento remoto e geoprocessamento aplicados ao zoneamento ecológico-econômico e ao ordenamento territorial. São José dos Campos: INPE , 2001. 124p.

EMPRESA BRASILEIRA DE PESQUISA AGROPECUÁRIA - EMBRAPA. Centro Nacional de Pesquisa de Solos. Sistema brasileiro de classificação de solos. 2. ed. Rio de Janeiro, 2006. 306p.

ENVIRONMENTAL SYSTEMS RESEARCH INSTITUTE - ESRI. The new ArcGIS at 10.1. Redlands, 2013.

FARIA, A. L. L. D.; SILVA, J. X. D.; GOES, M. H. D. B. Análise ambiental por geoprocessamento em áreas com susceptibilidade à erosão no solo da Bacia do Ribeirão do Espírito Santo, Juiz de Fora (MG). Caminhos de Geografia, Uberlândia, v. 4, n. 9, p. 50-65, jun 2003.

FARIA, M. M.; FERNANDES FILHO, E. I. Avaliação dos algoritmos SVM e Maxver para a classificação de sistemas florestais monodominantes de candeia (Eremanthus sp.) In: SIMPÓSIO BRASILEIRO DE SENSORIAMENTO REMOTO, 16., 13-18 Abr., Foz do Iguaçu. Proceedings... São José dos Campos: INPE 2013. p.3222-3229.

FUNDAÇÃO ESTADUAL DO MEIO AMBIENTE - FEAM (MG). Mapa de solos do Estado de Minas Gerais: legenda expandida. Belo Horizonte, 2010. 49p.

IPPOLITI R, G. A.; COSTA, L. M. D.; SCHAEFER, C. E. G. R.; FERNANDES FILHO, E. I.; GAGGERO, M. R. Análise digital do terreno: ferramenta na identificação de pedoformas em microbacia na região de "Mar de Morros" (MG). Revista Brasileira de Ciência do Solo, Viçosa, v. 29, p. 269-276, 2005. 
JENSON, S. K.; DOMINGUE, J. O. Extracting topographic structure from digital elevation data for geographic information system analysis. Photogrammetric Engineering and Remote Sensing, v. 54, n. 11, p. 1593-1600, 1988.

JUIZ DE FORA. Companhia de Sanemanto Municipal - CESAMA. Mananciais: Ribeirão Espíriro Santo. Juiz de Fora, 2010. Disponível em: <http://www.cesama.com.br/? pagina=resanto $>$. Acesso em: 10 dez. 2013.

KLAIS, T. B. A.; DALMAS, F. B.; MORAIS, R. P.; ATIQUE, G.; LASTORIA, G.; FILHO, A. C. P. Vulnerabilidade natural e ambiental do município de Ponta Porã, Mato Grosso do Sul, Brasil Revista Ambiente \& Água, Taubaté, v. 7, n. 2, p. 277-290, 2012. http://dx.doi.org/10.4136/ambi-agua.786

LIMA, C. D. S.; CORRÊA, A. C. D. B.; NASCIMENTO, N. R. D. Analysis of the morphometric parameters of the rio Preto basin, Serra do Espinhaço (Minas Gerais, Brazil). Geociências, São Paulo, v. 30, n. 1, p. 105-112, 2011.

LIMA, R. M. S. (Elab.). Cartas IBGE, escala 1:50.000 - folhas Ewbank da Câmara e Juiz de Fora. Modelo digital de elevação. Juiz de Fora: Prefeitura municipal, 2013.

LIMA, W. D. P. A silvicultura e a água: ciência, dogmas e desafios. Rio de Janeiro: Instituto BioAtlântica, 2010. 54p.

MACHADO, P. J. D. O. Diagnóstico ambiental e ordenamento territorial - instrumentos para a gestão da Bacia de Contribuição da Represa de Chapéu D’Uvas/MG. 2012. 243f. Tese (Doutorado em Geografia) - Universidade Federal Fluminense, Niterói, 2012.

MELO, O. A. G. D.; SANTOS, M. L. D. Análise comparativa da vulnerabilidade ambiental potencial ou emergente da Bacia Hidrográfica do Rio Baiano - Assis Chateaubriand/PR. Boletim de Geografia, Maringá, v. 28, n. 2, p. 17-27, 2010. http://dx.doi.org/10.4025/bolgeogr.v28i2.10375

NARDINI, R. C.; POLLO, R. A.; CAMPOS, S.; BARROS, Z. X. D.; CARDOSO, L. G.; GOMES, L. N. Análise morfométrica e simulação das áreas de preservação permanente de uma micobacia hidrográfica. Irriga, Botucatu, v. 18, n. 4, p. 687-699, 2013.

NASCIMENTO, D. M. C.; DOMINGUEZ, J. M. L. Avaliação da vulnerabilidade ambiental como instrumento de gestão costeira nos municípios de Belmonte e Canavieiras, Bahia. Revista Brasileira de Geociências, São Paulo, v. 39, p. 395-408, 2009.

OLIVEIRA, F. P. de; FERNANDES FILHO, E. I.; SOARES, V. P.; SOUZA, A. L. D. Mapeamento de fragmentos florestais com monodominância de aroeira a partir da classificação supervisionada de imagens RapidEye. Revista Árvore, Viçosa, v. 37, n. 1, p. 151-161, 2013. http://dx.doi.org/10.1590/S0100-67622013000100016

OLIVEIRA, P. T. S. D.; RODRIGUES, D. B. B.; SOBRINHO, T. A.; ELÓIPANACHUKI. Processo analítico hierárquico aplicado a vulnerabilidade natural a erosão. Geociências, São Paulo, v. 28, p. 417-424, 2009.

PIMENTEL, D. Soil erosion: a food and environmental threat. Environment, Development and Sustainability, v. 8, p. 119-137, 2006. http://dx.doi.org/10.1007/s10668-005$1262-8$ 
POLETO, L. J. D. C.; SILVA, C. H. C. D.; JÚNIOR, S. R.; VIEIRA, C. A. O.; SANTOS, A. D. P. D. Validação de Modelo Digital de Elevação Hidrologicamente Consistente (MDEHC) In: SIMPÓSIO BRASILEIRO DE CIÊNCIAS GEODÉSICAS E TECNOLOGIAS DA GEOINFORMAÇÃO, 2., 8-11 Set., Recife. Proceedings... Recife: UFPE, 2008. 1 CD-ROM.

POORE, M. E. D.; FRIES, C. The ecological effects of eucalyptus. Roma: FAO, 1985. 88p.

RIBEIRO, F. L.; CAMPOS, S. Vulnerabilidade à erosão do solo da Região do Alto Rio Pardo, Pardinho, SP. Revista Brasileira de Engenharia Agrícola e Ambiental, Campina Grande, v. 11, n. 6, p. 628-636, 2007. http://dx.doi.org/10.1590/S141543662007000600012

ROCHA, J. S. M. D.; KURTZ, S. M. D. J. M. Manual de Manejo Integrado de Bacias Hidrográficas: 4. Santa Maria: CCR/UFSM, 2001. 302p.

ROCHA, R. M.; LUCAS, A. A. T.; ALMEIDA, C. A. P. D.; NETO, E. L. M.; NETTO, A. D. O. A. Caracterização morfométrica da sub-bacia do rio Poxim-Açu, Sergipe, Brasil. Revista Ambiente \& Água, Taubaté, v. 9, n. 2, p. 276-287, Apr. / Jun. 2014. http://dx.doi.org/10.4136/ambi-agua.1289

ROSS, J. L. S. Análises e sínteses na abordagem na abordagem geográfica da pesquisa para o planejamento ambiental. RDG Revista do Departamento de Geografia da Universidade de São Paulo, São Paulo, v. 8, p. 65-75, 1994.

SANTOS, A. M. D.; TARGA, M. D. S.; BATISTA, G. T.; DIAS, N. W. Análise morfométrica das sub-bacias hidrográficas Perdizes e Fojo no município de Campos do Jordão, SP, Brasil. Revista Ambiente \& Água, Taubaté, v. 7, n. 3, 2012. http://dx.doi.org/10.4136/ambi-agua.945

SILVA, J. L.; TONELLO, K. C. Morfometria da bacia hidrográfica do Ribeirão dos Pinheirinhos, Brotas - SP. Irriga, Botucatu, v. 19, n. 1, p. 103-114, Jan. / Mar. 2014.

SOUZA, K. R.; VIEIRA, T. G. C.; ALVES, H. M. R.; ALVES, M. L. V.; ANJOS, L. A. P. D.; SOUZA, C. G.; ANDRADE, L. N. Classificação automática de imagem do satélite RapidEye para o mapeamento de áreas cafeeiras em Carmo de Minas, MG. In: SIMPÓSIO DE PESQUISA DOS CAFÉS DO BRASIL, 7., 22-25 Ago., Araxá. Proceedings... Araxá: Consórcio Pesquisa Café, 2011. 1 CD-ROM.

THOMAZ, E. L.; ANTONELI, V. Erosão e degradação do solo em área cultivada com ervamate (Ilex paraguariensis), Guarapuava - PR. Geociências, São Paulo, v. 27, p. 21-30, 2008.

VALlADARES, G. S.; GOMES, A. D. S.; TORRESAN, F. E.; RODRIGUES, C. A. G.; GREGO, C. R. Modelo multicritério aditivo na geração de mapas de suscetibilidade à erosão em área rural. Pesquisa Agropecuária Brasileira, Brasília, v. 47, n. 9, p. 13761383, set. 2012. http://dx.doi.org/10.1590/S0100-204X2012000900023

VERÍSSIMO, M. E. Z.; NOVO, E. M. L. M.; VERÍSSIMO, C. U. V. Estudo da Bacia Hidrográfica do Rio Passaúna-PR, através de parâmetros morfométricos da rede de drenagem. Revista de Geologia, Fortaleza, v. 9, p. 97-109, 1996.

VILLELA, S. M.; MATTOS, A. Hidrologia aplicada. São Paulo: Mc Graw Hill, 1975. 245p. 